\title{
The National Junior Horticultural Association: Serving Youth and Horticulture
}

The National Junior Horticultural Association (NJHA) is the only organization dedicated solely to youth and horticulture. NJHA programs are designed to help youth understand and develop skill in the art and science of horticulture, provide opportunities to increase written and verbal communication skills, and hone leadership skills. These programs help the horticultural industry by recruiting youth into horticulture and training them in many specialized fields of horticulture. NJHA also develops citizen appreciation of the industry by placing emphasis on positive programs for building producer-consumer understanding (Fountain, 1990).

NJHA has as its mission to offer a diverse palette of opportunities and experiences for youth age 22 and under, whether they are interested in horticulture as a vocation or avocation. Among these are the horticulture photography contest an example of which is illustrated on the cover of this issue of HortScience. Projects sponsored by NJHA are listed in Table 1.

Leadership and program coordination is provided by youth officers and a network of adult state leaders. Additional information is available from me.

College-bound youth and their parents invariably express concern about college funding. As students become involved in a curriculum, financial concerns are joined by worries of obtaining practical experiences in their chosen profession. Recognizing, these concerns, NJHA has sought to develop programs that will provide some financial relief and educational opportunities for outstanding individuals.

Parental and student concerns for college tuition are not unfounded. In recent years, college tuition has increased more rapidly than the rate of inflation or personal income. For the academic year of 1976-1977, private college tuition averaged $16.5 \%$ of median family income, while 4-year public institutions averaged $4.1 \%$. By the 1987-1988 academic year, tuition had increased to $22.1 \%$ and $4.8 \%$, respectively (DeLoughry, 1990b). In the past 3 years, public colleges have increased tuition an average of $4 \%, 8 \%$, and $7 \%$. The average cost for tuition room, board, books, supplies, and transportation was $\$ 6991$ for in-state students attending a public university and living on campus in 1990 (DeLoughry, 1990a). J.A. Davis, president of the U.S. Student Association notes that "federal student aid has not

Front cover: "Lemon Lilies", taken by Heidi Voth, Red Wing, Minn., as part of the photography exhibition at the 1990 NJHA convention. kept pace with tuition increases in the 1980s" (DeLoughry, 1990b). This leaves a significant shortfall in financial aid available to college students. Some 1990-91 freshman classes decreased by as much as 35\% (Wilson, 1990), which invariably has affected enrollment in at least some horticulture curricula.

Employers in the horticultural industry frequently complain that graduates have little or no practical experience in traditional horticulture. When confronted with this, students cite the need to work at jobs that will yield the greatest rate of financial savings possible. Living at home while not in school limits the type of employment

As part of its goals, NJHA has set a high priority for providing opportunities that will help youth entering the horticultural profession. Two specific examples are the Scottish Gardening Scholarship and the Armstrong Scholarship for Achievement and Leadership.

\section{Scottish Gardening Programs}

The Scottish Gardening Program is administered by NJHA in conjunction with the Scottish-American Heritage Foundation and the Threave School of Gardening in Castle Douglas, Scotland. For many years, Long wood Gardens, Kennett Square, Pa., has had a program allowing foreign students to continue their horticultural education at their facilities. Many of these students came from Scotland. This was, in part, due to the large number of gardens and estates in the United Kingdom, with emphasis on horticulture as a vocation and the quality of professional training that students received prior to arrival at Longweed Gardens. As a result of this long-standing relationship, the Scots felt drawn to reciprocate. This has evolved into the program as it is today.

The Scottish Gardening program, which began in 1967, allows an American student to study European horticultural techniques for 1 year. These activities are centered around the program of the National Trust for Scotland's Threave School for Practical Gardening, located at Castle Douglas, Kirkcudbrightshire. Castle Douglas, a 25-ha estate, is one of the National Trust estates found throughout the United Kingdom and was formerly the home of Major Alan Gordon. Since 1960, it has -tuated the traditional skills of the Scottish gardener. Bill Hean, principal at Threave, and four instructor gardeners are responsible for the 8 hours of classroom instruction and 32 hours of hands-on instruction provided weekly.

The curriculum is designed for ornamental horticulture students ages 18 to 21 interested in working in some segment of the industry. In addition to private estates, botanic gardens, arboreta, and sites that are part of the National Trust, it also includes garden centers and contracting and other segments of the ornamental industry. The program is designed to have a very practical hands-on approach.

Major instructional emphasis is placed on plant material. The climate in this part of Scotland, warmed by the Gulf Stream, allows for the culture of an extremely wide range of plant material from around the world. Most American exchange students entering the program have completed 1 to 3 years of college and generally have a keen interest in plant materials. Returning exchange students frequently work in the installation and maintenance of landscape plants.

Learning to recognize and produce plants of superior quality is the ultimate goal of this program. Needless to say, mass production so common in U.S. society, is not the chief objective. The primary objective of the Threave School of Practical Gardening is to train gardeners for estates and other facilities that, because of limited capital, size, and demand for suprior quality, rely primarily on hand labor rather than machinery.

While at Threave, it is possible for American students to visit and study at other wellknown gardens such as Edinburgh, Kew, and Wisley, and the vast number of National Trusts located throughout the United Kingdom. Many of the exchange students also visited gardens on the European continent. Exchange students are provided with roundtrip air fare, tuition, room and board, and a stipend of $\$ 100$ per month.

Students that have participated in this program have generally had good experiences. However, as Clink Taggart, a 1977 exchange

Table 1. Projects sponsored by NJHA.

1) Achievement and leadership recognition project (Armstrong Scholarship)

2) Demonstration contests

A. Production

B. Marketing

C. Use

D. Artistic arrangement

E. Landscaping

F. Special division

3) Speech contests

A. Illustrated talk

B. Speech

C. Extemporaneous speaking

D. Special division

4) Environmental beautification project report

5) Experimental horticulture project report

6) Production and marketing project report

7) Horticulture contest

8) Scottish Gardening Scholarship

9) Photography contest

10) Young America Horticulture Project Reports
A. Gardening
B. Plant propagation
C. Environmental beautification
D. Experimental horticulture

11) Poster contest 
student stated, "You get out of the program what you put into it." As one of the first American exchange students, he finds himself returning to Scotland almost every year to renew friendships. While there, he takes the Opportunity to visit the vast network of gardens in the National Trust.

Taggart enrolled in the program because he wanted to travel and see the world. He states that the Threave program allowed him the "opportunity to live in a 19th century Scottish baronial mansion, experience Scottish culture and lifestyle, and the chance to study a wide variety of plant materials." His experiences ranged the whole gambit of practical horticulture from fruit and vegetable culture to rock gardens, conifers, and alpine plants, annuals, perennials, heathers, and landscape design and history.

Taggart, who is now employed at Colonial Williamsburg in Virginia says that this was a "fantastic opportunity for a 21 -year-old." $\mathrm{He}$ advises participants "to go with your eyes wide open and without preconceived notions. Go with anticipation of getting as much as possible out of the experience. There are differences in climate, culture, and food that will provide experiences for a lifetime."

Andrew L. Clark, of South Bend, Ind., is the 1991 recipient of the scholarship. He is a 1989 graduate of La Salle High School, in South Bend, where he was a Latin Scholar, National Honor Society Member, and Presidential Academic Achievement Award winner. Clark is pursuing a career in landscape gardening through self-employment and is eager to advance his studies in historic garden preservation.

Students interested in additional information and applications should contact Clara Curtis, The North Carolina Arboretum, P.O. Box 6617, Asheville, NC 28816-6617 (phone 704/665-2492). The deadline for applications is $31 \mathrm{Dec}$., with the 1-year program beginning the following August. An interview during the annual NJHA convention, generally the last weekend in October, is suggested, but not required. In the event that a qualified applicant is not found, the scholarship will not be awarded.

\section{Armstrong Scholarship for Achievement and Leadership}

The Armstrong Scholarship for Achievement and Leadership is offered to an individual, age 15-22, who has excelled in activities and leadership connected with NJHA and other organizations. This endowed scholarship has been given by the family of Cassius and Pauline Armstrong, who have been associated with NJHA for the past 40 years.

Jack Armstrong and Jill Thompson inaugurated this award to honor their parents. With guidance from their parents, they each won grand national awards in the NJHA production and marketing project report and served as youth leaders. Armstrong says "programs offered by NJHA... [formerly called the National Junior Vegetable Growers Assn.]... are important not just for the understanding of horticulture, but also for their contribution to our personal growth and development. While not entering horticulture as a profession, we realize the importance of horticultural activities and products in our daily lives. Since we both entered education as life-long professions, we felt that a scholarship would be an appropriate acknowledgement of the importance of education in the development of today's youth leaders."

Gwendolyn Hartley Pemberton, a Univ. of Kentucky horticulture graduate from Maysville, Ky., was the first (1989) recipient of this award. She stated that "many highly qualified students mistakenly neglect to apply for this and other scholarships because they do not think that they are qualified. In reality, they may be the most qualified." Pemberton is now a graduate student at North Carolina State Univ., Raleigh.

The 1990 recipient of the scholarship is Connie Carney, of Homer City, Pa. She is a freshman in horticulture at The Pennsylvania State Univ., New Kensington, and plans to use her scholarship to participate in afield study of aquatic biological systems and to purchase books related to her horticultural studies.

There is a limit of two applicants per state, with selection at the state level by the NJHA state leader or state committee. Applicants must submit a resume, a report detailing their leadership activities, and be interviewed at the NJHA annual convention. A major in horticulture is not a necessity. Personal or family income is not a criteria for selection, and there are no minimum standards for grade point average, ACT/SAT score, etc. While academic standing and curriculum are important, this is a scholarship for leadership. Setting minimum standards may well eliminate certain individuals who would just miss a numenCal cutoff.
The winner receives a plaque and a $\$ 500$ scholarship, which is to be used for further study. These funds maybe used for, but are not limited to, traditional university studies. Examples of nontraditional horticultural studies include vocational education and travel to gardens, seminars, and other activities. Up to three additional individuals will receive plaques as national award winners. In the event that an applicant of sufficient quality does not apply, the scholarship will not be awarded.

information on these and other NJHA programs is available in the NJHA Project and Activities Guide for Contestants and Leaders. A copy may be obtained at no charge from your NJHA state leader or me.

\section{Literature Cited}

DeLoughry, T.J. 1990a. Fees sise more slowly this year, but surpass inflation rate again. Chron. Higher Educ. 37(5):A1, A36.

DeLoughry, T.J. 1990b. Education secretary calls on colleges to hold down costs. Chron Higher Educ. 37(14):A1, A26.

Fountain, W.M. 1990. National Junior Horticultural Project and Activities Guide for Contestants and Leaders. NJHA, Fremont, Mich.

McDonald, W.N. (ed.). 1976. Threave students honor Longwood with bicentennial stairway. Scottish-American Heritage Nwsl. Sept. 1976.

McDonald, W.N. (ed.). 1977. SAH exchange students report on life at Longwood, 'heave. Scottish-American Heritage Nwsl. Dec. 1977.

McDonald, W.N. (ed.). 1978. Letters from SAH students at Threave report school, Scotland full of rewarding experiences. Scottish- American Heritage Nwsl. June 1978.

Wilson, R. 1990. Many institutions report sharp drop in freshman roll. Chron. Higher Educ. 37(5):A1, A35.

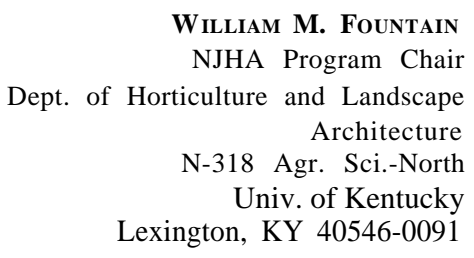

William M. Fountain

iculture and Landscape Architecture Univ. of Kentucky Lexington, KY 40546-0091 